\title{
19 The Systemic Constellations Method Applied to Agriculture
}

\author{
Melissa Roussopoulos \\ Forgotten Connections
}

\section{CONTENTS}

Introduction 219

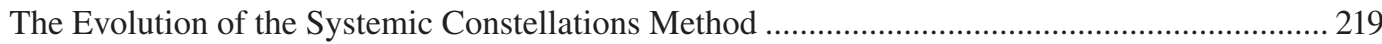

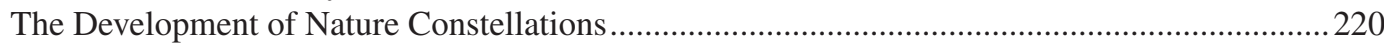

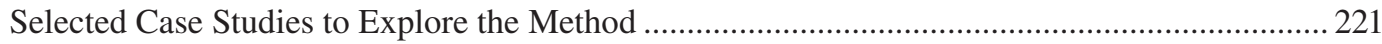

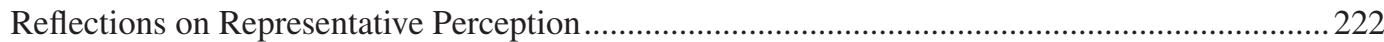

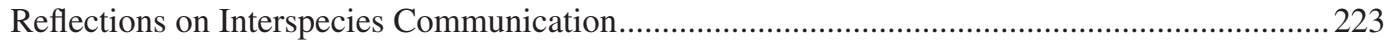

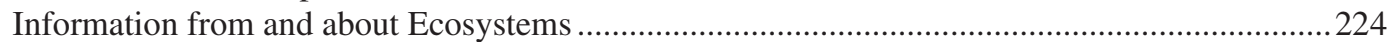

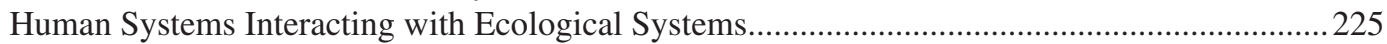

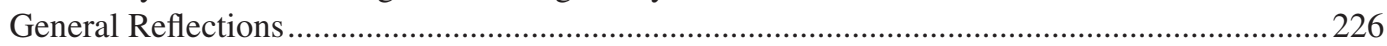

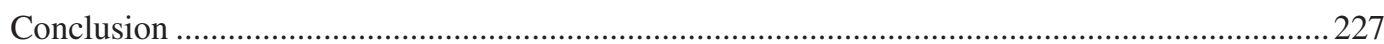

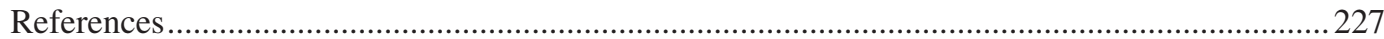

\section{INTRODUCTION}

Systemic Constellations is an experiential group methodology that reveals the usually invisible dynamics of complex systems. This essay charts its evolution into a series of forms that have successfully provided insights and solutions in a range of professional fields. Most recently, it has been applied to systems which include animals, plants and various components of ecosystems.

Research by the author is presented through case studies to illustrate this application and explore the questions it raises, in particular whether the information that emerges is coming from other-than-humans. The evidence strongly suggests that it is, and further case studies demonstrate ways in which the method can be of value within agriculture.

\section{THE EVOLUTION OF THE SYSTEMIC CONSTELLATIONS METHOD}

The method was developed by Bert Hellinger in Germany to help clients resolve their personal issues. He was trained in various Western therapeutic modalities and was also influenced by the indigenous knowledge and understanding of the Zulu people, having spent 16 years among them in South Africa (Franke, 2003).

A trained facilitator (the Constellator) would address a client's issue in a workshop setting with a group of people who were not related to the client. This process was called a 'Constellation' and it began with the Constellator interviewing the client to identify the individuals in the client's family who might be relevant to his/her issue. The client would then choose individuals from the present group to 'represent' these family members. These 'representatives' (reps) were then intuitively positioned by the client to stand in specific places in the room. From wherever they were placed, the reps would describe what they felt in their bodies, their emotional state and their relationships with the other reps.

The author's first experience as a rep was in 2000, when a client invited her to represent her sister. She was positioned among five or six other reps, and then suddenly found herself intensely angry, 
specifically with a male rep standing about $2 \mathrm{~m}$ behind her. She had never met the man being the rep before, nor did she know which family member he was representing. Intensely surprised by the strength of the anger, as well as the fact that she was feeling it, she reported it to the Constellator. He told her that this was the kind of information they were looking for, then the client revealed that the man the author was angry with was representing her father and 'my sister hates my father'.

Hellinger had discovered that reps, who had no previous knowledge of the client or of his/her family, reported information which was accurate for the member of the family they were representing. He could not explain this phenomenon, called 'representative perception', but he observed that it took place consistently.

The initial positioning of the reps was found to reflect the current dynamics between the family members. The Constellator would then facilitate a process during which reps moved or spoke. The other reps reported how these actions impacted them and, over a long period of experimentation, what emerged were repeating patterns in the experiences of the reps. From these, as well as family therapeutic understanding, interventions were developed to support the healthier functioning of family systems. Through these, the clients' issues would be resolved.

This first form of Constellations emerging in the 1990s became known as 'Family Constellations'. It identified two foundational elements on which all subsequent evolutions of Systemic Constellations (the generic term) are based. The first is the use of representative perception as a consistent and valid way to access information. The second is the understanding that individuals are profoundly influenced by the systems of which they are a part. Individuals inevitably belong within their family systems, but they are also part of the organisational systems where they work, the social and cultural systems within which they live and the natural systems which sustain them.

By the mid 1990s, the Constellations methodology was being applied to organisational systems (Organisational Constellations). Workshops took the same format with clients, a Constellator and a group, but the issues were professional and the reps took roles not only as other people, but also as internal teams, the whole organisation, its customers or even abstract concepts such as 'purpose'. As before, reps would experience sensations in their bodies and feelings about the other reps. Crucially, their experiences made sense in the context and led to insights and solutions. Organisational Constellators identified interventions that supported organisational systems to thrive and the method proved successful for companies such as Daimler-Chrysler, IBM and BMW (Horn and Brick, 2009).

In 2004, the International Forum for System Constellations in Organisations (infosyon) was founded in Germany, developing quality standards, training standards and a code of conduct. Along with certifying facilitators and training courses, the Forum supports ongoing interdisciplinary research and development into the method. Some of the many theses written about Organisational Constellations can be found on its website ${ }^{1}$ and it has links to a group of professors and lecturers who are researching and using the method within European universities. The Forum's most recent bi-annual conference in 2018 attracted participants from 18 countries. ${ }^{2}$

Beyond family and organisational systems, Constellators have been developing the method for use in a range of fields including politics, drug rehabilitation, education and prisons. Many academic papers and books now exist on these topics; Constellations conferences have taken place throughout Europe, in North and South America, Australia and South Africa; and there are trainings and professional bodies in a number of countries.

\section{THE DEVELOPMENT OF NATURE CONSTELLATIONS}

In 2003, the author, an environmentalist by background, witnessed an Organisational Constellation which indicated that the methodology might be able to help with environmental questions. She trained in Organisational and Family Constellations and then held a post researching the application

\footnotetext{
${ }^{1}$ www.infosyon.com.

2 Personal communication with Katrina Barry, Chairperson of infosyon, November 2019.
} 
of Constellations in different professional fields. Through facilitating exploratory Constellations on a range of issues involving human and ecological systems, she developed her approach. Over a similar period, an international group of Constellators began to explore using Systemic Constellations with nature. They conducted experiential research in many domains including: domesticated animals, forest management, the healing properties of plants and international environmental issues (Mason Boring, 2007). The first book about what have come to be known as Nature Constellations (NCs) features 14 practitioners working in 5 countries, the common thread being the inclusion of other-than-humans in their Constellations (Mason Boring and Sloan, 2013).

\section{SELECTED CASE STUDIES TO EXPLORE THE METHOD}

Since 2014, and inspired by collaborations with academics in the agricultural sector, the author has been formally researching some of the NCs she facilitates: obtaining informed consent, audio recording NCs and interviewing clients afterwards to track the impacts. Case studies from this work are presented below to illustrate the method, investigate the questions it raises and assess its potential to address agroecological issues. (Unless otherwise stated, all NCs described were run by the author and names have been changed.)

\section{Case Study 1: A Home for a Horse}

Phoebe and her mother owned and cared for a horse, Mascot. When her mother died, Phoebe had to choose where Mascot would live. At the time he was staying with a woman who kept him as a companion for her own horse, but Phoebe felt she would be letting her mother down if she did not look after Mascot herself. She undertook a NC to help her decide.

Phoebe chose a rep to be Mascot and he reported that he felt pain in his right wrist. When she set up a rep for herself (P), P described having a heavy, burdened feeling in their belly area. When $\mathrm{P}$ tested how it would be to have Mascot living with her, as an option within the NC, P burst into tears saying 'I'm in crisis, I can't take on any more'. At some point Mascot's rep said 'I want to be with other horses'.

The best outcome was shown to be for Mascot to be with another horse and not living with Phoebe. Attention was also paid to Phoebe's feelings of letting her mother down and to resolving these.

During the follow-up interview, Phoebe revealed that she had been sceptical about the method to start with. Thus, when Mascot's rep had reported pain in his right wrist, she had been shocked. Mascot had navicular syndrome, a degenerative disease in his right front fetlock - equivalent to where the rep had experienced pain in his body - and Phoebe had not said anything about this to the group. For Phoebe, this was an 'a-ha' moment and helped her to trust what was unfolding. It also transpired that Phoebe had a medical condition in her belly (also unmentioned), the same area her rep had felt heavy and burdened.

At the time of the NC, Phoebe was caring for various members of her family and was not well herself. Had Mascot been moved to live with her, it would have added a considerable burden in terms of time and energy, particularly as she would have had to take on a second horse to keep him company. Phoebe later explained that she has a strong tendency to take on too much responsibility, without realising the negative impacts on herself: 'so it was very powerful to see someone representing me go in and just have a complete melt down and say "I can't cope".

Phoebe reported that the NC had helped her decide to keep Mascot where he was and 'I... stopped beating myself up about the horse being with someone else'. Five years later, she is clear that her life has been easier through not having had to look after him and Mascot is thriving with his caretaker and horse companion. 


\section{REFLECTIONS ON REPRESENTATIVE PERCEPTION}

On learning how reps spontaneously experience body sensations, emotions or just 'know things' relevant to their roles, people often question if it is really happening. The best way to answer this question is to directly experience it. While case studies can describe it, and the entire Constellations field attests to it, any written account of representative perception falls short of the actual experience. A participant at a NC workshop in 2012 described representing for the first time: 'I found it amazing how easy it was to tune into non-human consciousness in a whole-body experience and for it to be so obvious that I was not making up or imagining the experiences I was having'.

The next question is usually to ask how it could be happening. In 2006, the author identified a number of potential scientific explanations (Roussopoulos, 2006) and since then advances in consciousness studies, science and cosmology have led to more integrated and complete explanations (Laszlo et al., 2016). However, representative perception has successfully underpinned Systemic Constellations for decades without practitioners knowing how it works.

The author holds that the most important question for agricultural applications of NCs is to ask where the information is coming from. If the data about the human/ecological system in question originates, consciously or unconsciously, solely from the client or holding group, it is merely someone's belief, or at best second-hand information. Two phenomena have been observed in all forms of Systemic Constellations which indicate that reps may be picking up their data directly from the beings they are representing. The first is when information emerges in a Constellation which no-one present knows about and which is subsequently proven to be accurate. The second is when something spontaneously changes in the system being represented, in line with what happened within the Constellation, but where there has been no contact between the people present at the Constellation and the beings in the actual system. The next two case studies illustrate these phenomena taking place in NCs.

\section{Case Study 2: Struggling Cabbages}

Laura wanted to know what she could add to the soil to support the health of her cabbages. A female rep for the cabbages $(\mathrm{C})$ initially reported that her roots needed to be stronger and that she felt vulnerable to being nibbled. C's body was leaning over, her top half moving in circles around her torso as if her head were very heavy. She would go down, then just about manage to pull herself up. Laura, watching from the sidelines, commented that perhaps the cabbages had not had time to grow good roots and she was concerned that the rep, C, would fall over. Laura could have added manure, lime or biodynamic preparations to the soil, so reps were brought in for each of these options. C experienced a jolt when the biodynamic preparations came in, and then found that the manure felt better to her. However, only the presence of lime stabilised her movement.

Not long after the NC Laura contacted the author, very excited - she had just uncovered her cabbages, which had been under fleece for the previous 4-5 months. They were a type of cabbage that would usually stand upright with their heads on stalks about six inches high. She had been expecting to find small, under developed heads, instead of which: 'to my utter amazement... they had actually grown so enormous that they couldn't hold their own weight on the stalks... they had toppled... I've never seen them fall over before... so it completely reflected what the representative was doing'.

Neither Laura, nor anyone else in the group, had known the state of her cabbages when she did the NC. The behaviour of rep C - leaning over with a heavy head - accurately mirrored the heavy heads of the actual cabbages. Also, as such big heads were unusual, Laura had not anticipated them. The 
information revealed through rep $\mathrm{C}$ could not have come from Laura or the group, consciously or unconsciously.

\section{Case Study 3: A Traumatised Dog}

In October 2016, an incredibly friendly, mainly Fox Terrier mongrel, Tommy, witnessed his owner being killed. Tommy continued to live in the same home as before with his owner's partner, Paul, but his behaviour totally changed. He became extremely clingy and demanding, unable to tolerate being left alone. In March 2017, Paul did a short NC about Tommy. Five days later he wrote: 'When I got home, late evening, Tommy greeted me in a sedate and very peaceful manner. Having been locked up in the house all day, he would normally go ballistic. It was astounding how different he was. What is more, he has been much calmer with me since'.

Perhaps being left alone all day had somehow cured the dog, but when questioned about this during a follow-up interview, Paul felt that this was unlikely because Tommy had never enjoyed being alone. Another possibility was that, on his return, Paul had behaved differently to Tommy, which is why Tommy's response had changed. Paul, however, insisted that his own behaviour had not altered and was convinced that the NC was responsible for the healing in Tommy. Five months later, Paul reported that Tommy had never reverted to his previous extremely anxious behaviour.

There is thus the possibility that the NC itself impacted Tommy as it took place, which suggests a connection between the rep for Tommy, or some other aspect of the NC, and Tommy himself.

\section{REFLECTIONS ON INTERSPECIES COMMUNICATION}

While the two case studies above do not prove that the reps' information comes from the other-than-humans being represented, Nature Constellators' consistent and extensive experiences lead them to believe that it does. In addition, the multiple case studies demonstrating the success of the NCs method make it probable (Mason Boring and Sloan, 2013; Roussopoulos, 2018).

In the author's opinion, a NC involves the human reps in the Constellation connecting directly with the actual humans and other-than-humans who are being represented. This would mean that NCs facilitate distant two-way communication between humans and other-than-humans, a proposition generally considered impossible within mainstream western culture and academia.

M. J. Barratt, Assistant Professor at the University of Saskatchewan, observes that the existence of communications from other-than-humans is 'acknowledged and experienced by many, both Indigenous and non-Indigenous' (Barratt, 2011: 125). In her opinion, these communications are downplayed within academia, which considers rationality and the intellect to be the primary, if not the only, valid ways of knowing. Animistic methods of research, on the other hand, validate the body as capable of receiving information and create spaces "where the "voices" of other-than-human "persons" (in their many forms) can be heard' (Barratt, 2011: 134). Scientific experiments indicate that telepathic interspecies communication is the most likely explanation for certain observed phenomena (Sheldrake and Morgana, 2003) and a few academics are beginning to address how this might work (Erickson, 2011).

The author has listened, formally and informally, to personal accounts of interspecies communications from many people, including farmers, vets, indigenous trackers, a professor of consciousness studies, agricultural researchers, shaman and professional animal communicators. All were certain that they had experienced communication with other-than-humans, be they animals, plants or areas of land. The following case studies describe NCs that are relevant for the agricultural sector and an opportunity to reflect on whether these NCs are indeed a form of interspecies communication. 


\section{INFORMATION FROM AND ABOUT ECOSYSTEMS}

\section{Case Study 4: Bees in the Bush}

Francesca Mason Boring teaches a range of Systemic Constellations forms including NCs. When a $\mathrm{NC}$ reveals information which could have public benefit, she obtains the group's agreement to waive confidentiality so that the learning can be disseminated. Hence, she could report on a NC she facilitated in a coastal community (Mason Boring and Sloan, 2013: 13-14). The NC included a rep for a bee, and Mason Boring became nervous that there was no flower for the bee. The bee's rep told her that he did not need a flower because 'I am very strong when I stand by this bush'. The bush being represented grew in the local area.

Mason Boring shared that she did not understand why the bee did not need a flower, only to discover that someone in the group was a biologist with a specialty in botany. He was astounded by what had happened and was able to explain it. The bush in question had an extremely high protein content. Come spring time, as the bees came to life in that cold region, they could quickly find the most efficient food source through that bush. In Mason Boring's opinion, the NC demonstrated that the bees needed that specific bush. Unfortunately, the bush was considered unattractive and was becoming very rare.

This case study indicates that NCs have the potential to show what other-than-humans need in order to thrive, as well as the inter-relationships between parts of an ecosystem. The botanist's knowledge provided verification that the relationship described was accurate. Since pollinators, such as bees, are crucial to food production, such information could be invaluable for farmers.

\section{Case Study 5: Exploring Beneficial Growing Conditions}

In Greece, a grove of olive trees were getting old and their owner was considering adding animal manure and/or planting leguminous vetches to enrich the soil and hopefully strengthen the trees. She was about to start a NC to check which of these would best support the olives, when one of her employees mentioned that wild asparagus could be another option.

A rep for the olive trees (OT) was positioned and immediately said: 'I feel the roots but something is missing'. A rep for manure (M) was brought in, which made OT feel easier. OT had no response to a rep for the vetches (V), but when a rep for wild asparagus (WA) was brought in, she said: 'I feel better... I feel energy'. Combining WA with M, OT reported 'even better, more energy', however on adding V as well, OT said: 'it's OK but it doesn't make any difference'. She preferred to be without $\mathrm{V}$, while $\mathrm{V}$ reported feeling good but 'I don't feel any attachment to the olive'. OT consistently felt energy when WA was present. The NC indicated that the olive trees' preference was to have wild asparagus planted, as well as livestock manure added.

Afterwards, the employee shared that farmers used to plant olives together with wild asparagus, which she believed was because, in nature, the asparagus was found under olive trees. Neither the owner nor the person representing the olive trees had known this beforehand.

The olive tree rep feeling 'energy' in the presence of wild asparagus could imply a synergistic relationship between the two species, in which each supports the other. At the very least, the NC indicated a compatibility between olive trees and wild asparagus. A few years after this, the author learned of an EU-funded multi-stakeholder project which included development research and promotion of the mixed cropping of wild asparagus in olive orchards. Both species require the same growing conditions and it was found that growing asparagus under the olive trees did not reduce 
the olive yield. Having two crops raised the productivity of the land, requiring few additional inputs other than labour, while helping to protect farmers from extreme crop failure (Rosati, 2017).

On a few other occasions, the author has been able to check generic information about ecosystems learned from NCs against independent research, and each time the data matched, as per the above two case studies.

\section{HUMAN SYSTEMS INTERACTING WITH ECOLOGICAL SYSTEMS}

Farming involves both human and ecological systems and because Constellations always seek the well-being of the whole, both are taken into account. Organisational Constellations (OC) techniques can be brought in to support the organisational aspects of agriculture. OC theory holds that the purpose of any endeavour needs to be clear, appropriate and supported, while OC practices have developed so that activities can be planned over time in alignment with a purpose. These OC approaches were integrated into the series of NCs described below.

\section{Case Study 6: Vineyards Coming into Being}

Fenia had a project to develop 10 ha of mainly fallow land on a Greek island. Fruit, olive trees and aromatic herbs were already growing there, with some processing and selling of the produce. Tourists were staying in restored buildings on the site, however the total income only covered about a third of the maintenance costs. While Fenia was considering a range of income-generating options, she also had a strong desire to listen to the other-than-humans involved in the project.

In 2015, the author worked with Fenia to design a bespoke NCs workshop, both to get clarity about the next steps, and to co-create with nature. A rep for the 10 ha of land (Land) was set up in relation to a rep for Fenia's purpose for the project. Land expressed a strong need to be cultivated, specifically she wanted vineyards 'near the orange groves'. Fenia then revealed that this was exactly the area where vineyards were possible, and where it was likely that vines had been grown in the distant past. When a rep for Fenia's husband came in, it became clear that his priorities were in conflict with Fenia's stated purpose.

Fenia's husband had bought the land, so although Fenia was in charge, both were part of the project. A second NC identified a new purpose that was both welcomed by Land and supported by the reps of both Fenia and her husband. This made it possible to run a third NC to assess which of the proposed activities would best support the fruition of this purpose. To do this, a rep was set up for the whole project (Project), who described feeling big already 'but I feel the potential of a bigger scale'. Reps for various possible next steps were being introduced to identify which of them had a place, when Project spontaneously stated 'I want the vineyard'. When a rep for a vineyard (V) was brought in, Project responded 'I feel very positive excitement for the vineyard here'. V remained close to the Project as other future steps were evaluated in relation to the new purpose.

Immediately after the NCs, Fenia described having learned 'implicit things in this which are something we couldn't have presupposed without this work. [One is that] the vineyard will generate an empowerment that will make other things happen easier'.

Interviewed 2 weeks later, Fenia explained that she had considered a vineyard on the land but 'personally it was an option that was sounding a bit too much for me... a very ambitious project... I did have a prejudice against it'. Because of what she had seen and heard, she was no longer so dismissive of the idea.

Over the next few years, the island unexpectedly developed an extremely good reputation for wine. Fenia's husband, who knew nothing about the NC work, proposed that they plant a vineyard to make wine. It was a long process that involved soil testing and gaining permissions from the Greek state, as well as EU funding to help build the wine making plant. Fenia - who was happy to do what she perceived the land itself wanted - was aligned with her husband throughout the process. 
In April 2019, they planted 11,000 vine roots over an area of $30,000 \mathrm{~m}^{2}-$ in precisely the location that the rep for the $10 \mathrm{ha}$ of land had identified in the first NC. This area was ten times the $3,000 \mathrm{~m}^{2}$ that Fenia had originally considered planting and which, in 2015, had felt too intimidating for her. In July 2019, Fenia described how beautiful the vineyard looked and how their commitment to it had enabled many other aspects of the wider project on the land to gel together. She felt that things were falling into place and confirmed that all their activities were in line with the new purpose identified back in 2015 .

OCs sometimes refer to 'the future that wants to emerge'. Could this be what was identified through the NCs for Fenia? What does it mean for a piece of land to have a desire, for a 'project' to ask for vineyards to be included? NCs challenge many of our assumptions about where consciousness is located and how information flows between different consciousnesses. But NCs are not alone: evidence from a wide range of disciplines indicates that a new paradigm is both required and emerging (Laszlo et al., 2016). NCs provide a method and data that could support the development of such a new paradigm.

\section{GENERAL REFLECTIONS}

Apart from the preceeding case studies, Mason Boring and Sloan (2013) and Roussopoulos (2018) describe how NCs have already demonstrated their value for a range of agricultural and environmentally-related issues. These include: the specific relationship dynamics between particular humans and other-than-humans; the general relationships that hold within ecosystems; planning of land development projects; support for environmental and agricultural organisations; and explorations of global environmental and policy issues. After 15 years facilitating NCs and tracking the results where possible, the author's assessment is that NCs constitute a form of interspecies communication that could support agriculture in countless ways.

The method continues to evolve, and research is ongoing to build understanding of what they are capable of, the reliability of the data, and how and when they can best be implemented. Collaboration between Nature Constellators and researchers within the agricultural field would enhance this process, while also contributing to the theory and practice of sustainable farming.

NCs are themselves an innovative form of research into human/ecological systems. Agricultural systems are coming under increasing pressure through climate change, pollution and other stressors, and deeper insights into these complex and rapidly shifting systems are essential. Systemic Constellations evolved to map and work with the interconnected dynamics of complex systems that more linear or traditional research methods fail to grasp. NCs can do this for agroecosystems. They can provide information about systems' dynamics in real time and track the relationships between the different parts. Proposed actions could be tested within NCs and, through the reps' responses, the likely impacts on the whole system would become visible - impacts that modern reductionist science is unable to predict and which could serve as signposts for further investigation.

Finally, NCs bring benefits beyond simply providing information. Other-than-human reps regularly offer their own suggestions, so the process becomes not just co-operative, but co-creative. There may be spontaneous positive changes in the system represented, not to mention in the client present. A few months after doing a NC about the projects on his farm, the owner wrote: 'the end [of the Constellation]... was so fantastic that I broke down crying when I related it to my wife and even got emotional when sharing it with other people'. Frequently clients and reps experience profound shifts in their relationships with the other-than-human life around them towards more understanding, appreciation and respect. 


\section{CONCLUSION}

Nature Constellations is a relatively new development of the Systemic Constellations methodology and has only recently been applied in the agricultural field. The research presented indicates that NCs can access accurate information about the other-than-human life around us, effectively forming a means of communication with it. While further research into NCs would hone their application, they have already demonstrated their value in addressing agroecological issues, particularly when integrated with the theory and practice of Organisational Constellations.

As well as addressing specific questions brought by clients, NCs offer a unique method of research into human/ecological systems which could supplement traditional agricultural research. By providing insights into the current state of agroecosystems, revealing the relationships between the parts and indicating what would benefit the whole system, NCs could make a valuable contribution to the thriving of all life.

\section{REFERENCES}

Barratt, M. J. (2011) Doing animist research in academia: A methodological framework. Canadian Journal of Environmental Education 16:123-137.

Erickson, D. L. (2011) Intuition, telepathy, and interspecies communication: A multidisciplinary perspective. NeuroQuantology 1:145-152.

Franke, U. (2003) The river never looks back: Historical and practical foundations of Bert Hellinger's family constellations. Heidelberg: Carl-Auer-Systeme Verlag.

Horn, K. P. and Brick, R. (2009) Invisible dynamics: Systemic constellations in organisations and business, Second Edition. Heidelburg: Carl-Auer-Verlag.

Laszlo, E., Dennis, K. L., et al. (2016) What is reality: The new map of cosmos and consciousness. New York: SelectBooks Inc.

Mason Boring, F. (2007) Nature constellations: Mother Earth belongs. The Knowing Field International Constellations Journal 9:14-17.

Mason Boring, F. and Sloan, K. E. (eds) (2013) Returning to membership in Earth community: Systemic constellations with nature. Pagosa Springs, Colorado: Stream of Experience Productions.

Rosati, A. (2017) Wild asparagus in olive orchards: Get more income from your orchard. Agroforestry Innovation Leaflet 19. Available online: www.agforward.eu/index.php/en/intercropping-and-grazingof-olive-orchards-in-italy.html (accessed 23rd June 2020).

Roussopoulos, M. (2006) Anyone know the URL for the truth? Science and constellations. The Knowing Field International Constellations Journal 8:16-21.

Roussopoulos, M. (2018) Nature constellations: Exploring our profound interconnectedness with all life. The Knowing Field International Constellations Journal 31:61-71.

Sheldrake, R. and Morgana, A. (2003) Testing a language-using parrot for telepathy. Journal of Scientific Exploration 17:601-615. 